\title{
The Interaction of Grazing Muzzle Use and Grass Species on Forage Intake of Horses
}

\author{
Emily C. Glunk ${ }^{1}$, Craig C. Sheaffer ${ }^{2}$, Marcia R. Hathaway ${ }^{3}$, and Krishona L. \\ Martinson ${ }^{4}$ \\ ${ }^{1}$ Graduate Research Assistant, Department of Animal Science, University of \\ Minnesota \\ ${ }^{2}$ Professor, Department of Agronomy and Plant Genetics, University of Minnesota \\ ${ }^{3}$ Professor, Department of Animal Science, University of Minnesota \\ ${ }^{4}$ Associate Professor, Department of Animal Science, University of Minnesota
}

\begin{abstract}
Excessive pasture intakes have been linked to the increase in incidence of equine obesity. Previous research with grazing ponies showed that grazing muzzles reduced pasture intake by $83 \%$. However, horses are selective grazers, and forage grasses have different growth morphologies (i.e. upright and prostrate). Both of these factors could impact the effectiveness of grazing muzzles; however, this has not been researched. Therefore, the objective of this experiment was to determine the effectiveness of grazing muzzles at reducing forage intake when horses were allowed access to different grass species. Four adult horses, with a mean body weight of $460 \mathrm{~kg}$ (SD $\pm 107 \mathrm{~kg}$ ), were grazed in a Latin square design. Prior to grazing, horses were acclimated to wearing the grazing muzzle (Weaver, Mt. Hope, $\mathrm{OH}$ ) and to grazing for the prescribed amount of time. Four species of perennial, cool-season grasses were grazed, including Kentucky bluegrass (KB), meadow fescue (MF), perennial ryegrass (PR), and reed canarygrass $(R C)$. KB and MF were previously determined to be preferred by horses, while PR and $\mathrm{RC}$ were less preferred. $\mathrm{KB}$ and PR have prostate growth habits, while MF and RC have upright growth habits. Horses were grazed in June and August of 2012 in St. Paul, MN. Horses were allowed to graze a small pasture $(4.5 \times 9.9 \mathrm{~m})$ for 4 hours each day for 4 consecutive days each month. On days 1 and 2, horses were given access to one grass species either with or without a grazing muzzle. On days 3 and 4 , horse were given access to a different grass species either with or without a grazing muzzle. Prior to each grazing event, a $0.9 \times 3.3 \mathrm{~m}$ strip was mechanically harvested from the pasture to determine available initial herbage mass. Post grazing, an adjacent $0.9 \times 3.3 \mathrm{~m}$ strip was harvested to determine residual forage mass. The difference (on a dry matter basis) was used to estimate horse pasture intake. After grazing, manure was removed and pastures were mowed and allowed to re-grow. Data was analyzed using the PROC MIXED procedure of SAS, with statistical significance set at $P \leq 0.05$. Grazing muzzles decreased $(P=0.0014)$ the amount of herbage mass consumed by $45,38,30$, and $4 \%$ when horses grazed PR, KB, MF, RC, respectively. The combination of prostrate growth and low preference resulted in the greatest reduction in forage mass consumed when muzzled horses grazed PR. Although RC had an upright growth habit, low horse preference resulted in a minimal reduction of forage mass consumed when grazed by muzzled horses. These preliminary results suggest that the effectiveness of grazing muzzles in reducing herbage mass intake depends on the grass being grazed.
\end{abstract}

